ARCHIVO ESPAÑOL DE ARTE, XCIII, 370

ABRIL-JUNIO 2020, pp. 147-152

ISSN: 0004-0428, eISSN: 1988-8511

https://doi.org/10.3989/aearte.2020.10

\title{
VARIA
}

\section{SOBRE UN GRABADO DE GUILLAUME ANABAT Y LA ICONOGRAFÍA DE LA VENIDA DEL ESPÍRITU SANTO DE JUAN DE FLANDES}

\author{
Whitney DenNis ${ }^{1}$ \\ Universidad de Alcalá
}

Esta nota realiza algunas consideraciones sobre el uso de un grabado de Guillaume Anabat para La venida del Espíritu Santo de Juan de Flandes; también de una miniatura de Sander Bening para la tabla del mismo tema en el Políptico de Isabel la Católica; además plantea cuestiones sobre la formación del pintor.

Palabras clave: Juan de Flandes; Pentecostés; Sander Bening; Simon Bening; Guillaume Anabat.

\section{AN ENGRAVING BY GUILLAUME ANABAT AND THE ICONOGRAPHY OF THE DESCENT OF THE HOLY SPIRIT BY JUAN DE FLANDES}

This paper brings to light the use of an engraving by Guillaume Anabat for The Descent of the Holy Spirit by Juan de Flandes in comparison with the use of a miniature by Sander Bening for a panel of the same subject in the Polyptych of Isabella I, which gives rise to some questions on the artist's training.

Key words: Juan de Flandes; Pentecost; Sander Bening; Simon Bening; Guillaume Anabat.

Cómo citar este artículo / Citation: Dennis, Whitney (2020): "Sobre un grabado de Guillaume Anabat y la iconografía de La venida del Espíritu Santo de Juan de Flandes". En: Archivo Español de Arte, vol. 93, núm. 370, Madrid, pp. 147-152. https://doi.org/10.3989/aearte.2020.10.

Dentro de un escenario político tenso por el conflicto de intereses entre el señorío eclesiástico, el concejo local y los nuevos mandatarios reales en Palencia², Juan de Flandes completó allí los últimos trabajos de su carrera, encargados por don Sancho de Castilla ${ }^{3}$, el obispo Juan Rodrí-

1 w.dennis@edu.uah.es / ORCID iD: https://orcid.org/0000-0002-1355-1237

2 Sobre la tensión entre el obispado y el concejo en Palencia y el papel central que tendría Sancho de Castillo en ello en 1500 véase Suárez, 1987: 330.

3 Sobre la vida de Sancho de Castilla, poco se sabe a pesar de la relevancia de los cargos que desempeñó: descendiente de una rama bastarda del rey Pedro I llamado el Cruel, fue ayo del príncipe Juan, el único hijo varón de los Reyes Católicos, también maestresala de los reyes, capitán exitoso que participó en la guerra civil "como ferviente isabelino" y miembro del Consejo Real; en 1472 Enrique IV le hizo señor de Herrera de Valdecaña convirtiéndolo en un vecino noble de Palencia, y fue nombrado alcaide de León en 1475 y de Zamora en 1477; Isabel aprobó nuevamente la concesión de tierra en Palencia a Sancho en una carta en 1481, pero no antes de unos años de servicio fiel dentro círculo más íntimo de los Reyes Católicos del cual formó parte oficialmente desde el año 1479, pues sucedió a Juan de Zapata como ayo del Príncipe Juan, recibiendo entonces el salario más alto de la Casa Real, año que también entró en el Consejo Real, y solo un año después de la intervención militar de 1480 que el Consejo Real facilitó dando licencia 


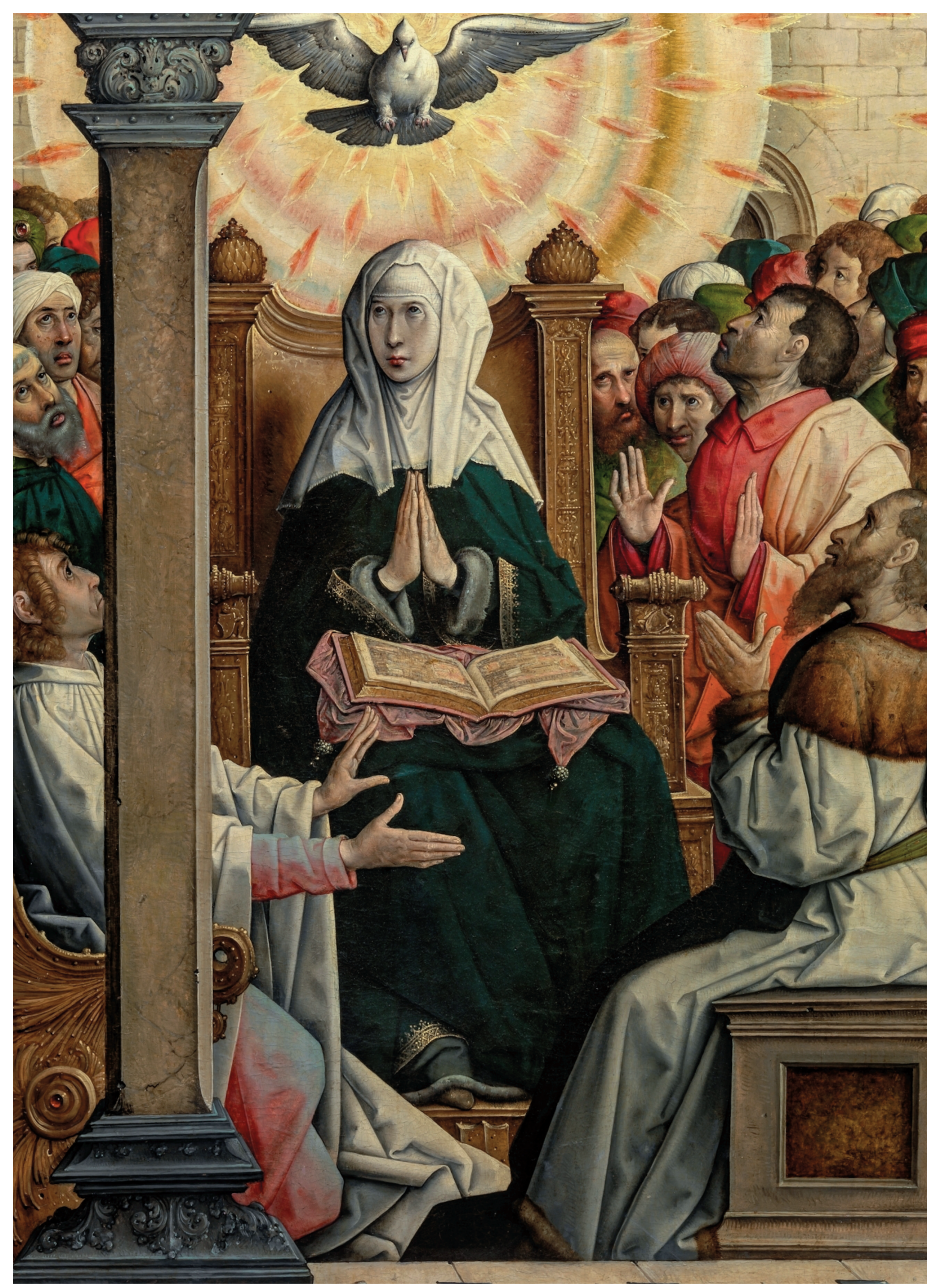

Fig. 1. Juan de Flandes: La venida del Espiritu Santo o Pentecostés (1514-1519), procedente del retablo mayor de la Iglesia de San Lázaro, Palencia. Museo Nacional del Prado, Madrid (P-2938).

guez de Fonseca y el Almirante Fadrique Enríquez; tres figuras estrechamente vinculadas a la corte de los Reyes Católicos, como el mismo pintor ${ }^{4}$. Seguramente las pinturas que realizó para el retablo mayor de la iglesia de San Lázaro de Palencia fueron comisionadas por Sancho de Castilla: En 1505 su hijo Sancho murió en Toro después de una carrera militar exitosa, dejando a su padre una renta con el mandato de hacer una capilla y fundar sobre ella ciertas capellanías, en 1508 Sancho obtuvo el patronato de la iglesia con el visto bueno del obispo Rodríguez de Fonseca, mientras la reina doña Juana aprobó por su parte la dotación y donación a la misma de seis capellanes, y aprovechó así la oportunidad para reconstruir en gran parte el templo que es-

de armas a Antonio de Merodio en Palencia para calmar la revolución allí contra el señorío eclesiástico, un asunto que indudablemente le interesó personalmente al ex-capitán, cuyos terrenos en aquella ciudad, concedidos previamente por Enrique IV, parecían necesitar de la aprobación de los monarcas actuales. Entre 1489 y 1495 aparecieron asientos a su favor que rondaban unos 25.000 maravedís anuales; al parecer para compensar por la quitación del cargo del ayo del príncipe en 1490. Se sabe que en 1494 estuvo en Toro, pues consta que el 19 de julio de ese año contrató allí a Fernando Gallego para que pintase las tablas del retablo de la capilla mayor de San Lorenzo de Toro, lugar donde estaban sepultados los padres de Sancho, Pedro de Castilla y Beatriz de Fonseca. A continuación, tenemos noticia de él en la administración palentina en el año 1500, Sancho de Castilla, quien se refirió a si mismo en su testamento como "hechura de los Reyes Católicos", falleció pocos meses después de Juan de Flandes en 1519. Véase: Gómez, 2009: 445-446; Ruíz García, 2007: 215; Silva, 2004: 67; 2006: 70-72; Suárez, 1987: 330, 332.

4 Silva, 2006: 60-73. 


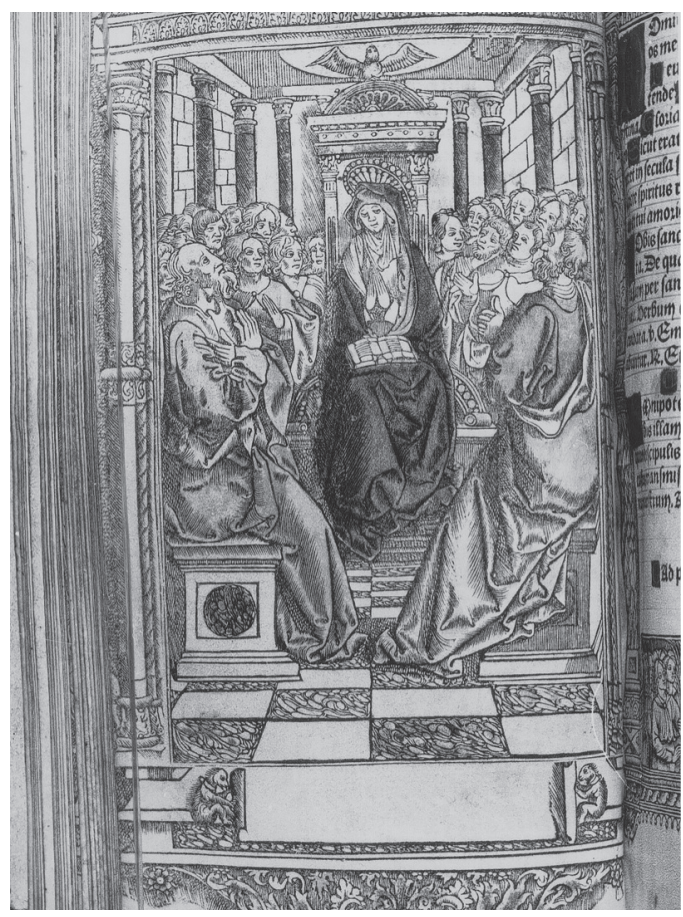

Fig. 2. Guillaume Anabat: Heures à l'usage de Rome (1505-1510). Bibliothèque National de France, París (BPT6K1510136M).

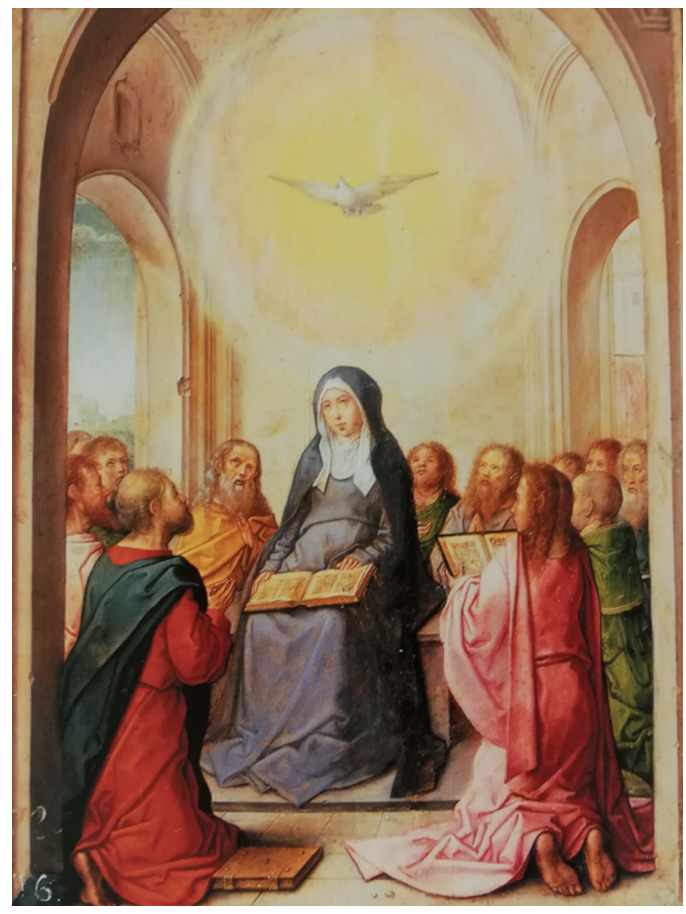

Fig. 3. Juan de Flandes: Pentecostés (1496-1504), procedente del políptico de Isabel la Católica. Patrimonio Nacional, Madrid (10002018 a 10002032).

taba necesitado de reforma, y lo adaptó como lugar de enterramiento familiar ${ }^{5}$. La fecha de inicio de funcionamiento de la iglesia fue el 1 de enero de 1519; el 3 de marzo del mismo año se realizó un inventario exhaustivo, pero cabe notar que en él no se mencionó el retablo de Juan de Flandes, por lo que se puede deducir que las pinturas seguían en su taller ${ }^{6}$.

La venida del Espíritu Santo en el Museo del Prado [fig. 1] formó parte del retablo mayor de esta iglesia. Fechada entre 1514 y 1519, muestra una imagen del Pentecostés poco común por representar a la Virgen sentada en una magnífica cátedra, muy poco habitual en las representaciones de este pasaje. Hasta donde sabemos, solo existen dos precedentes pictóricos con la representación de la Virgen María entronizada en esta escena. Un pintor anónimo brujense del último tercio del siglo XV representa a la Virgen sentada en un trono bajo un dosel ${ }^{7}$, y según Silva, el Maestro de San Nicolás (posiblemente Diego del Corral), activo en Burgos entre 14651490 , representó a la Virgen sentada en un trono en el retablo de Oña ${ }^{8}$.

\footnotetext{
5 Silva, 2006: 72; Estrada, 2007: 303, 307-308.

${ }^{6}$ La primera noticia sobre el retablo apareció en 1761. Después del cierre de la iglesia por hundimiento en 1945, se tuvo noticia de que seis de las ocho tablas que formaban parte del retablo se encontraban en una colección privada de Palencia; seguido por un intento de su venta al exterior en 1952, si bien en ese mismo año cuatro de ellas acabaron ingresadas en el Museo del Prado, mientras las otras dos sí fueron exportadas al año siguiente, y al final se integraron en la colección de Samuel H. Kress, la misma colección en la cual aparecieron las otras dos tablas del retablo original, de las que hasta entonces no se tenían noticias; y estas cuatro tablas terminarían ingresando en la National Gallery of Art in Washington en 1961. Silva, 2006: 415-417. Sobre el inventario, véase: Estrada, 2007: 321-323; Visitas, inventarios y cuentas 1519-1607. Parroquia de San Lázaro, Archivo del Diócesis de Palencia, Palencia (ADP), Libro no.100, fols. 5-14v.

7 Resulta muy diferente a la tabla de Juan de Flandes. El tríptico estuvo en la galería de Rob Smeets en 1994, y ahora se encuentra en una colección privada. Martens / Mund, 2003: 30. Para imágenes del tríptico completo, véase De Vos, 1994: 233-235.

${ }^{8}$ Desgraciadamente la calidad de la imagen del retablo es peor de lo deseable y no se percibe con nitidez la imagen de María entronizada, además la tabla no ha sobrevivido para poder compararlas. Silva, 1990: 268-269.
} 
En 1508, Billet Hardouin imprimió en París un libro de horas, Heures à l'usage de Rome , en el cual apareció un grabado del Pentecostés [fig. 2] realizado por Guillaume Anabat ${ }^{10}$ que presenta muchos puntos de similitud con la tabla de Juan de Flandes en el Museo del Prado. Uno es especialmente llamativo: el trono de María. En el grabado se aprecia un grupo numeroso de personas formado por los apóstoles y discípulos que, apiñados en una masa apretada, colman el espacio que hay detrás de la Virgen María, así como a ambos lados de ella, como sucede en la pintura de Juan de Flandes. La Virgen está, igualmente, sentada en el trono, con un gran libro abierto en las rodillas y las manos juntas sobre el pecho, en un gesto orante, ensimismada y sin dirigir la mirada hacia la paloma como hacen todos los presentes. Por último, destaca la similitud que hay entre la figura de la túnica roja a la derecha de la Virgen en la tabla y la figura con un traje y gesto parecidos también a la derecha de María en el grabado. La rareza de la presencia del trono y las similitudes en la composición, así como la disposición, los atributos y los gestos de las figuras en las dos representaciones, sugieren que Juan de Flandes tuvo acceso a este grabado y que la imagen influyó en su concepción para La venida del Espíritu Santo de San Lázaro en Palencia. Como ha señalado Silva, la composición de Juan de Flandes también recuerda a una escena de Los Siete Gozos de la Virgen María albergado en el Alte Pinakothek de Múnich del maestro brujense Hans Memling de 1480, que representa una disposición similar de las figuras y un gesto parecido en la Virgen María, si bien con algunas diferencias notables ${ }^{11}$.

Poco se sabe sobre la vida y el trabajo de Guillaume Anabat, impresor y grabador en París entre 1505 y 1510, quien estampó varios libros de horas, como sus múltiples versiones del Heures à l'usage de Rome que contiene el grabado inédito en cuestión ${ }^{12}$. La comparación de esta obra tardía con el Pentecostés que formó parte del Políptico de Isabel la Católica (1496-1504), se evidencia la variedad de composiciones que Juan de Flandes empleó a lo largo de su carrera. Algo que, como han señalado Silva y Weniger, dificulta sugerir una hipótesis firme sobre su formación en Flandes ${ }^{13}$.

Para el Pentecostés del Políptico, el artista tuvo conocimiento de algunas imágenes de esta escena realizadas entre Brujas y Gante hacia finales del siglo XV y comienzos del siglo XVI ${ }^{14}$. En particular la huella de Sander Bening, miniaturista activo en Gante entre 1469 y 1519, se percibe en la semejanza entre la tabla del Políptico (1496-1504) y un dibujo preparatorio del iluminador, cuya composición también se plasma en una miniatura del Pentecostés pintada por su hijo, Simon Bening (1483-1561), activo en Brujas, para el Breviario Grimani [figs. 3-5] ${ }^{15}$. Las similitudes se evidencian en la arquitectura, abierta por los tres lados, la Virgen elevada en el centro de la imagen rodeada por los apóstoles con el libro abierto sobre las rodillas, las dos figuras destacadas en primer plano, además del libro tendido en el suelo.

Las miniaturas de Simon Bening se han citado múltiples veces como posibles fuentes visuales para las pinturas de Juan de Flandes en su primera etapa en Castilla ${ }^{16}$, y aunque no es posible que

\footnotetext{
${ }^{9}$ Heures à l'usage de Rome, 1508, Bibliothèque Nationale de France, Département Arsenal, RESERVE 8-T-2520, $<$ https://gallica.bnf.fr/ark:/12148/bpt6k1510136m>.

10 Guillaume Anabat no aparece en los principales diccionarios de artistas y miniaturistas. Benezit, 1998; ThiemeBecker, 1986; Jeffares, 2006; Blättel, 1992.

11 Silva, 2006: 442.

12 "Guillaume Anabat", en: <https://catalogue.bnf.fr/ark:/12148/cb166388014> [10 oct 2018]. De la portada del libro, sabemos que Anabat vivió en la rue saint Jehan de Beauvays en París.

13 Silva, 2006: 78; Weniger, 2011: 186.

14 Para más sobre un modelo brujense del Pentecostés, véase: Martens / Mund, 2003.

15 Weniger, 2011: 228, n. 1161; Ishikawa, 2004: 164, n. 126.

16 Véase: Silva, 2006: 150-52; Urbach, 2001: 198-199; Ishikawa, 2004: 162, n. 62, p. 163, n.104; Ainsworth 1998: 41, fig. 51; Brinkmann / König, 1991: pp. 333-334. Urbach señala que la composición del Ecce Agnus Dei de Simon Bening para el Breviario Grimani está basada en una obra brujense perdida, y Silva afirma que Juan de Flandes tuvo presente alguna de estas en su versión para el retablo del Bautista en Miraflores. Ishikawa menciona dos ejemplos más, pero aclara que aparecen en obras anteriores a las que debieron tener acceso tanto Juan como Simon. El primer ejemplo son unos putti con guirnaldas de diferentes obras de Memling (Brinkmann / König, 1991: 333-334) que aparecen en el dibujo subyacente de las Bodas de Caná del Políptico de Isabel y en la ilustración del mismo tema de Simon para para el Breviario Grimani. El segundo ejemplo es, como ya había indicado previamente Ainsworth, una composición de
} 


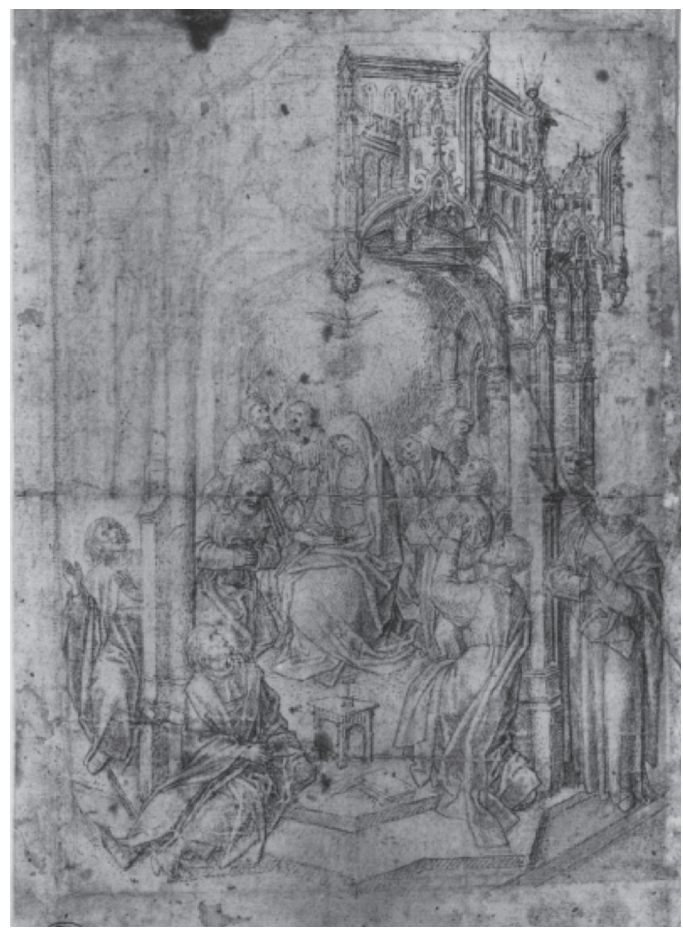

Fig. 4. Sander Bening: Dibujo preparatorio (c. 1500). Museum Boijmans Van Beuningen, Rotterdam (NK 124 recto $\mathrm{PK}$ ).

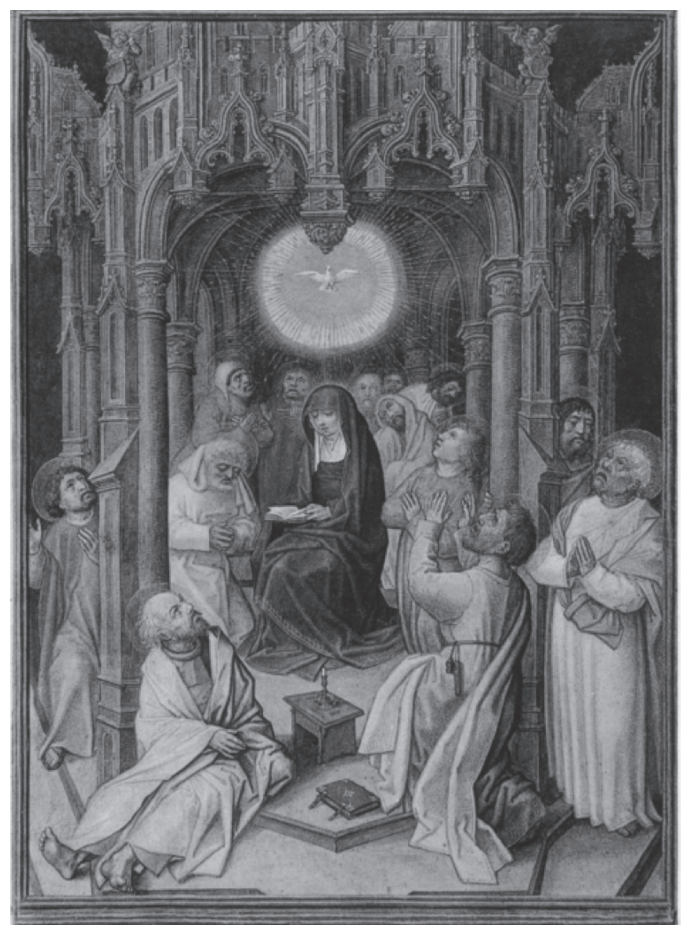

Fig. 5. Simon Bening: Pentecostés, del Breviario Grimani (c. 1515). Biblioteca Nazionale Marciana, Venecia (Ms. lat. XI 67 (7531), fol. 205v).

Juan coincidiera con Simon en Flandes durante su etapa como miniaturista profesional ${ }^{17}$, algunos elementos en sus composiciones parecen apuntar a experiencias paralelas. Sander Bening, amigo y posiblemente familia política de Hugo van der Goes ${ }^{18}$, tuvo su taller en Gante ${ }^{19}$. Juan de Flandes pudo conocer a los Bening allí, antes de partir a Castilla en 1496, lo cual reforzaría la hipótesis sobre su aprendizaje en el taller de van der Goes, establecido en la misma ciudad ${ }^{20}$.

No obstante, que Juan de Flandes conociera las obras producidas en el taller de Sander Bening no descarta otras teorías sobre su formación, porque pudo haber accedido a ellas también desde Brujas $^{21}$. Las obras de los Bening no son los únicos ejemplos de la influencia de la escuela de Gan-

Sander Bening del Museum Boijmans Van Beuningen, que se emplea en la Transfiguración de Juan de Flandes y en la lámina del mismo tema de Simon Bening en el Breviario Grimani. Weniger también hace mención de algunas de las conexiones entre las pinturas de Juan de Flandes y las de Simon Bening. Weniger, 2011: 215, 222, 250, 255.

17 Simon solo tenía trece años cuando Juan se instaló en Castilla en el año 1496 (la fecha de su nacimiento lo verifica Simon mismo en un autorretrato en que indica su edad); además, Simon no se registró en el gremio en Brujas hasta 1508. Véase Kren / McKendrick, 2003: 447-449, Ainsworth, 1998: 143, 220.

${ }^{18}$ Kren / McKendrick, 2003: 447-449. La madre de Simon Bening, y se supone la mujer de Sander, se llama Catherine Van der Goes, tal vez una hermana o hija del pintor.

19 Sander tuvo su taller en Gante. Su hijo, Simon, se trasladó a Brujas en 1500. Véase Kren / McKendrick, 2003: 447-449; Ainsworth, 1998: 143, 220; Martens / Mund, 2003: 22.

20 A pesar de que los estudios más recientes apuntan a su formación con Hans Memling, después de los estudios de Winkler en 1924, se había pensado que Juan de Flandes se formó en la escuela de Gante, en el taller de Hugo van der Goes, con grandes influencias de Justo de Gante y el llamado Maestro de María de Borgoña, el miniaturista del Libro de Horas de Engelberto de Nassau; Vandevivere fue de la misma opinión, basándose sobre todo en la composición pero también en el estilo; no obstante, muchos de los ejemplos que empleó Vandevivere se fundaron en atribuciones equivocadas y por lo tanto han perdido su validez. Silva, 2006: 34, 78-80. Para más sobre las teorías del aprendizaje de Juan de Flandes, véase: Winkler, 1924: 185; Winkler, 1925: 104; Vandevivere, 1967: 55-56; Weniger, 1997; Weniger, 2011: 183-189.

${ }^{21}$ Silva, 2006: 80-81. 
te en su obra ${ }^{22}$, aunque parecen reflejar una relación que merece un estudio más profundizado. Como han explicado Weniger y Silva, Juan de Flandes fue un pintor de tal originalidad y versatilidad que no es sencillo localizar las imágenes que tomó como punto de partida para sus composiciones, y mucho menos desarrollar una hipótesis sobre su aprendizaje, pero no cabe duda de que el estudio de su estilo demuestra de manera convincente una formación con Memling ${ }^{23}$. Ambos resaltan que la comparación de las escenas pintadas para el Políptico de Isabel al llegar a Castilla con las que repitió en su etapa palentina al final de su carrera muestra la naturaleza impredecible del pintor al componer imágenes inesperadas ${ }^{24}$, tal y como corrobora el caso de la Venida del Espíritu Santo aquí estudiada.

\section{BIBLIOGRAFÍA}

Ainsworth, M. W. (1998): Gerard David. Purity of Vision in an Age of Transition. Nueva York: Metropolitan Museum of Art. Benezit, E. (1998): Dictionnaire des peintures, sculpteurs, dessinateurs, et graveurs. París: Gründ.

Blättel, H. (1992): Dictionnaire international peintures miniaturistes, peintures sur porcelain silhouettistes.

Brinkmann, B. / König, E. (1991): Simon Bening, Das Blumen-Studenbuch. Lucerna: Fak-simile Verlag.

De Vos, D. (1994): Hans Memling. Catalogue. Bruges: Designdruk Van Damme.

Estrada Nérida, J. (2007): "Noticias y documentos sobre la capilla mayor e iglesia de San Lázaro de Palencia". En: Publicaciones de la Institución Tello Téllez de Meneses 78, Palencia, pp. 295-342.

Gómez Hidalgo, I. (2009): Diccionario biográfico español: XII Carvajal — Cazalla. Madrid: Real Academia de la Historia.

Ishikawa, C. (2004): The Retablo de Isabel la Católica by Juan de Flandes y Michel Sittow. Turnhout: Brepols.

Jeffares, N. (2006): Dictionary of Pastellists before 1800. Londres: Unicorn Press.

Kren, T. / McKendrick, S. (2003): Illuminating the Renaissance: The Triumph of Flemish Manuscript Painting in Europe. Los Ángeles: Getty Publications.

Martens, D. / Mund, H. (2003): "Autour de la "Pentecôte Rapaert" du Maître des Portraits Baroncelli: Modèles et traditions dans la peinture brugeoise à l'aube des Temps modernes”. En: Jahrbuch der Berliner Museen, 45, Berlín, pp. 7-37.

Pächt, O. (1947): The Master of Mary of Burgundy. London, 1948.

Ruíz García, E. (2007): El imaginario de una reina: Páginas selectas del patrimonio escrito de Isabel la Católica. Toledo: AyN Ediciones.

Silva Maroto, P. (1990): La pintura hispanoflamenca en Burgos y Palencia: obras en tabla y sarga. Madrid: Sever-Cuesta.

Silva Maroto, P. (2004): Fernando Gallego. Salamanca: Caja Duero.

Silva Maroto, P. (2006): Juan de Flandes. Salamanca: Gráficas Verona.

Suárez Fernández, L. (1987): "Palencia en la época de los reyes católicos". En: Diputación Provincial de Palenica (ed.): Actas del I Congreso de Historia de Palencia. Tomo I: Fuentes documentales y edad media. Valladolid: Gráficas Andrés Martín, S.A., pp. 325-335.

Thieme, U. / Becker, F. (1986): Allgemeines Künstler-Lexikon, Band 2. Leipzig: E.A. Seeman Verlag.

Urbach, S. (2001): “An Ecce Agnus Dei Attributed to Juan de Flandes: A Lost Panel from a Hypothetical Altarpiece". Jaarboek Koninklijk voor Schone Kunsten, pp. 198-199.

Vandevivere, I. (1967): La Cathédrale de Palencia et l'iglise paroissiale de Cervera de Pisuerga. Les Primitifs Flamands, I. Corpus de la peinture des anciens Pays-Bas méridionaux au quinzième siècle, 10. Bruselas.

Weniger, M. (1997): "Bynnen Brugge in Flandern: The apprenticeships of Michel Sittow and Juan de Flandes". En Verougstraete, H. / Van Schoute, R. / Smeyers, M. (eds.): Memling Studies. Proceedings of the International Colloquium (Brujas, 10-12 noviembre 1994). Leuven: Peeters, pp.115-131.

Weniger, M. (2011): Sittow, Morros, Juan de Flandes. Drei Maler aus den Norden am Hof Isabellas von Kastilien. Alemania: Ludwig.

Winkler, F. (1924): Die altniederländische Malerei. Die Malerei in Belgien und Holland von 1400-1600. Berlin

Winkler, F. (1925): The Flämische Buchmalerei des XV und XVI. Jahrhunderts. Leipzig.

Fecha de recepción: 29-VIII-2019

Fecha de aceptación: 29-X-2019

22 Para más sobre la influencia del Maestro de María de Borgoña, Justo de Gante y Hugo van der Goes, véase Silva, 2006: 79-85, 365-367; Weniger, 2011: 183-189; Winkler, 1924: 185; Winkler, 1925: 104; Pächt 1947.

${ }_{23}$ Pieza fundamental de esta hipótesis es la atribución que Weniger ha hecho a Juan de Flandes de una Virgen con el Niño (paradero desconocido, en comercio en Nueva York en 1949), pintura probablemente hecha en Flandes que sigue un prototipo de Hans Memling. Juan de Flandes ejecutó otra versión durante su estancia en Palencia que hoy se encuentra en la Colección Várez Fisa. Weniger, 2011: 236-237; Silva, 2006: 85-88.

${ }^{24}$ Silva, 2006: 78; Weniger, 2011: 186. 